\title{
Simultaneous Estimation of Pantoprazole Sodium and Levosulpiride in Capsule Dosage Form by Simultaneous Equation Spectrophotometric Method
}

\author{
Dimal A. Shah, Akash Patel, Sunil L. Baldania, \\ Usmangani K. Chhalotiya, and Kashyap K. Bhatt \\ Indukaka Ipcowala College of Pharmacy, Beyond GIDC, P.O. Box No. 53, Vitthal Udyognagar, Gujarat 388 121, India \\ Correspondence should be addressed to Dimal A. Shah; dimalgroup@yahoo.com
}

Received 28 February 2013; Accepted 19 April 2013

Academic Editors: S. Rojas and Z. Wang

Copyright (C) 2013 Dimal A. Shah et al. This is an open access article distributed under the Creative Commons Attribution License, which permits unrestricted use, distribution, and reproduction in any medium, provided the original work is properly cited.

A simple, accurate, and precise spectrophotometric method was developed for simultaneous estimation of pantoprazole sodium and levosulpiride in capsule dosage form. Simultaneous equation was developed at 290 and $232 \mathrm{~nm}$. The method was found to be linear in the range of $4-12 \mu \mathrm{g} / \mathrm{mL}$ for pantoprazole sodium and $8-20 \mu \mathrm{g} / \mathrm{mL}$ for levosulpiride while accuracy of the method was confirmed by recovery studies of capsule dosage form and was found to be $100.23-100.99 \%$ and $100.51-100.94 \%$ for pantoprazole sodium and levosulpiride, respectively, in their capsule dosage form. The proposed method was validated and found to be accurate and precise. The method was successfully applied for the estimation of pantoprazole sodium and levosulpiride from their capsule dosage form.

\section{Introduction}

Pantoprazole sodium (PNT) is a sodium 5-(difluoromethoxy)-2-[[(3,4-dimethoxy]-2-pyridinyl) methyl] sulfinyl]-1Hbenzimidazole [1] (Figure 1); it is a proton pump inhibitor drug used for short-term treatment of erosion and ulceration of the esophagus caused by gastroesophageal reflux disease [2]. It has molecular formula $\mathrm{C}_{16} \mathrm{H}_{14} \mathrm{~F}_{2} \mathrm{~N}_{3} \mathrm{NaO}_{4} \mathrm{~S}$ with molar mass $405.36 \mathrm{~g} / \mathrm{mol}$ [1]. Levosulpiride (LVS) is an N-[(1-ethyl2-pyrrolidinyl)methyl]-2-methoxy-5-sulfamoylbenzamide (Figure 2); it is a new orally effective antipsychotic and a prokinetic agent reported to be a selective antagonist of dopamine $\mathrm{D}_{2}$ receptor activity on both central and peripheral levels. It is an atypical neuroleptic (S)-enantiomer of sulpiride having molecular formula $\mathrm{C}_{15} \mathrm{H}_{23} \mathrm{~N}_{3} \mathrm{O}_{4} \mathrm{~S}$ with molar mass $341.43 \mathrm{~g} / \mathrm{mol}$. Levosulpiride is also claimed to have mood elevating property and used in the treatment of psychoses [3], particularly negative symptoms of schizophrenia, anxiety disorders, dysthymia, vertigo, dyspepsia, irritable bowel syndrome, and premature ejaculation [4].
The literature review revealed that LC methods $[5,6]$ have been reported for the estimation of PNT. Various RPLC methods have been reported for the estimation of PNT in combination with domperidone [7] and naproxen [8,9], respectively. Derivative spectrophotometric method has been reported for the estimation of LVS in tablet dosage form [10]. Simultaneous estimation of LVS and esomeprazole by UV spectrometry has been reported [11]. LC method has been reported for estimation of LVS from human plasma [12]. LC method have been reported for the estimation of LVS in combination with esomeprazole [13] and rabeprazole [14, 15], respectively. RP-LC method has been reported for the estimation of PNT and LVS in the combined dosage form [16].

A comprehensive literature research revealed that no spectrophotometric method is reported for the estimation of PNT and LVS in pharmaceutical formulations. So, the purpose of the present study was to develop and validate spectrophotometric analytical method for the estimation of both drugs in combination. 
<smiles>COc1ccnc(C[S@](C)(=O)c2nc3cc(OC(F)F)ccc3[nH]2)c1OC</smiles>

FIGURE 1: Structure of pantoprazole sodium.<smiles>CCN1CCC[C@H]1CNC(=O)c1cc(S(N)(=O)=O)ccc1OC</smiles>

FIGURE 2: Structure of levosulpiride.

\section{Materials and Methods}

2.1. Apparatus. All the absorption spectra were recorded on UV-visible double beam spectrophotometer (UV-1700, Shimadzu Corp., Japan) with $1 \mathrm{~cm}$ quartz cell. The drugs and chemicals were weighed on Shimadzu electronic balance (AX 200, Shimadzu Corp., Japan).

2.2. Reagents and Materials. Analytically pure PNT and LVS were obtained as gift samples from Balaji Chemicals, Mumbai, India, and Corona Remedies Pvt. Ltd., India, respectively. The purity of PNT and LVS were found to be $99.52 \%$, and $99.15 \%$, respectively, according to the manufacturer's analysis certificates. Capsule formulation (Pantocid-L capsule, Sun Pharma. Ltd., India) containing labeled amount of $40 \mathrm{mg}$ of PNT and $75 \mathrm{mg}$ of LVS was used for the study. Methanol (E. Merck, Mumbai, India) used as a solvent was of analytical grade.

2.3. Preparation of Standard Stock Solutions. Stock solutions were prepared by accurately weighing $25 \mathrm{mg}$ each of PNT and LVS and transferring to two separate $25 \mathrm{~mL}$ volumetric flasks containing a few $\mathrm{mL}$ of methanol. The flasks were swirled to dissolve solids. Volumes were made up to the mark with methanol, which gave $1000 \mu \mathrm{g} / \mathrm{mL}$ of both the drugs. Aliquots from the stock solutions were appropriately diluted with methanol to obtain working standard solutions of $100 \mu \mathrm{g} / \mathrm{mL}$ of each drug.

2.4. Selection of Analytical Wavelength. For the development of simultaneous equation method, the wavelength maxima of both the drugs are required. The overlain spectra of PNT and LVS $(10 \mu \mathrm{g} / \mathrm{mL})$ showed that $290 \mathrm{~nm}$ is the wavelength maxima of PNT and that $232 \mathrm{~nm}$ is the wavelength maxima of LVS. So, $290 \mathrm{~nm}$ and $232 \mathrm{~nm}$ were selected for the formation of simultaneous equation (Figure 3).

2.5. Calibration Curves for PNT and LVS. Appropriate aliquots of PNT and LVS working standard solutions were taken

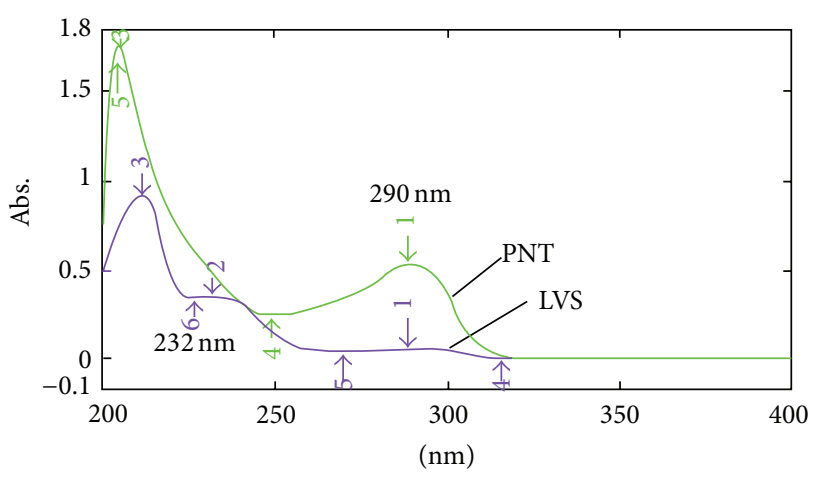

FIgURE 3: Overlain UV spectra of PNT and LVS.

TABLE 1: Summary of the validation parameters.

\begin{tabular}{lcc}
\hline Parameters & PNT & LVS \\
\hline Detection limit $(\mu \mathrm{g} / \mathrm{mL})$ & 0.4785 & 0.5301 \\
Quantitation limit $(\mu \mathrm{g} / \mathrm{mL})$ & 1.4500 & 1.6063 \\
Accuracy $\%)$ & $100.24-100.99$ & $100.52-100.95$ \\
Precision (\%RSD) & & \\
Intraday precision $(n=3)$ & $0.59-1.28$ & $0.65-1.37$ \\
Interday precision $(n=3)$ & $1.15-1.95$ & $1.05-2.23$ \\
Repeatability (\%RSD) & $0.38-0.69$ & $0.37-1.21$ \\
Robustness & $98.45-100.48 \%$ & $99.12-100.65 \%$ \\
\hline
\end{tabular}

in different $10 \mathrm{~mL}$ volumetric flasks and diluted up to the mark with methanol to obtain final concentrations of 4,6 , 8,10 , and $15 \mu \mathrm{g} / \mathrm{mL}$ of PNT and $8,10,12,15$, and $20 \mu \mathrm{g} / \mathrm{mL}$ of LVS, respectively. Spectra of the solutions were scanned between 400 and $200 \mathrm{~nm}$. The absorbance of solutions was measured at $290.0 \mathrm{~nm}$ and $232 \mathrm{~nm}$ against methanol as blank, and the absorbance versus concentration was plotted. The straight line equations for both drugs at two wavelengths were determined, and the values of $A_{1 \%}^{1 \mathrm{~cm}}$ were obtained.

2.6. Validation. The method was validated for accuracy, precision, specificity and robustness by following procedure.

2.6.1. Precision. The intraday and interday precision study of the proposed method were carried by measuring absorbance three times on the same day and on three different days for three different concentrations of PNT $(4,8$, and $12 \mu \mathrm{g} / \mathrm{mL})$ and LVS $(8,15$, and $20 \mu \mathrm{g} / \mathrm{mL})$, and the results reported in terms of RSD. The instrument precision was evaluated by estimating responses of three different concentrations of PNT (4, 8 , and $12 \mu \mathrm{g} / \mathrm{mL})$ and LVS $(8,15$, and $20 \mu \mathrm{g} / \mathrm{mL})$ six times and results reported in terms of relative standard deviation (RSD).

2.6.2. Accuracy. The accuracy of the method was determined by calculating recoveries of PNT and LVS by method of standard additions. Known amounts of PNT (0, 2, 4, and $6 \mu \mathrm{g} / \mathrm{mL})$ and LVS $(0,4,8$, and $12 \mu \mathrm{g} / \mathrm{mL})$ were added to a prequantified sample solutions, and the amount of PNT and LVS were estimated by proposed method. 
TABLE 2: Validation study using mixed standard.

\begin{tabular}{lccc}
\hline \multicolumn{2}{l}{ Amount of standard drug taken $(\mu \mathrm{g} / \mathrm{mL})$} & \multicolumn{2}{c}{$\%$ recovery \pm SD $(n=3)$} \\
PNT & LVS & PNT & LVS \\
\hline 4 & 8 & $100.78 \pm 1.76$ & $99.79 \pm 2.81$ \\
6 & 12 & $99.58 \pm 1.91$ & $99.39 \pm 2.16$ \\
8 & 16 & $100.80 \pm 0.81$ & $100.04 \pm 0.66$ \\
10 & 20 & $100.96 \pm 1.51$ & $99.62 \pm 0.46$ \\
\hline
\end{tabular}

TABLE 3: Analysis of marketed formulations.

\begin{tabular}{|c|c|c|c|c|c|c|}
\hline \multirow{2}{*}{ Formulation } & \multicolumn{2}{|c|}{ Labeled amount (mg) } & \multicolumn{2}{|c|}{ Amount found (mg) } & \multicolumn{2}{|c|}{$\%$ of drug found $\pm \mathrm{SD}^{*}$} \\
\hline & PNT & LVS & PNT & LVS & PNT & LVS \\
\hline Tablet 1 & 40 & 75 & 39.96 & 75.39 & $99.90 \pm 1.58$ & $100.52 \pm 2.01$ \\
\hline
\end{tabular}

${ }^{*}$ Mean value \pm standard deviation of three determinations; tablet: PANTOCID-L, Sun Pharma, Sikkim, India.

2.6.3. Specificity. For specificity study commonly used excipients present in selected capsule formulation were spiked into a preweighed quantity of drugs. The absorbance was measured, and the quantities of drugs were determined. The excipients used were talc, microcrystalline cellulose, starch (S. D. Fine chemicals, India), and carboxymethyl cellulose (Allied Chemical Corporation, India).

2.6.4. Robustness. Robustness of the method was studied by observing the stability of both drug solutions at $25 \pm 2^{\circ} \mathrm{C}$ for 24 h.

2.6.5. Laboratory Prepared Mixtures. Validity of formed equation has been checked by preparation of four mixed standards. Appropriate aliquots of PNT working standard solutions were taken in different $10 \mathrm{~mL}$ volumetric flasks. Appropriate aliquots of LVS working standard solutions were added to the same flask, and the volume was diluted to the mark with methanol to achieve final concentration of 4,6 , 8 , and $10 \mu \mathrm{g} / \mathrm{mL}$ of PNT and $8,12,16$, and $20 \mu \mathrm{g} / \mathrm{mL}$ of LVS. Spectra of solutions were scanned, and absorbance was measured at 290.0 and $232.0 \mathrm{~nm}$. Absorbance at these two wavelengths was substituted in the simultaneous equation to calculate the amount of the drug present.

2.7. Analysis of Marketed Formulations. Twenty tablets were weighed and finely powdered. Powder equivalent to $10 \mathrm{mg}$ of PNT (and $18.75 \mathrm{mg}$ LVS) was accurately weighed and transferred to a $50 \mathrm{~mL}$ volumetric flask. A few $\mathrm{mL}(20 \mathrm{~mL})$ of methanol was added to the above flask, and flask was sonicated for 5 minutes. The solution was filtered in to another $50 \mathrm{~mL}$ volumetric flask using Whatman filter paper (number 1), and volume was made up to the mark with the same solvent.

Appropriate volume of the aliquot was transferred to $25 \mathrm{~mL}$ volumetric flask, and the volume was made up to the mark with methanol to obtain $18.75 \mu \mathrm{g} / \mathrm{mL}$ of LVS (and $10 \mu \mathrm{g} / \mathrm{mL}$ of PNT). Spectra of solutions were scanned between 400 and $200 \mathrm{~nm}$, and the absorbance of the solution was measured at $290.0 \mathrm{~nm}$ and $232.0 \mathrm{~nm}$. Absorbance at these two wavelengths was substituted in the simultaneous equation to calculate the amount of the drug present.

\section{Results and Discussion}

For the development of simultaneous equation method the wavelength maxima of both drugs are required. The overlain spectra of PNT and LVS $(10 \mu \mathrm{g} / \mathrm{mL})$ showed that $290 \mathrm{~nm}$ is the wavelength maxima of PNT and that $232 \mathrm{~nm}$ is the wavelength maxima of LVS. So, $290 \mathrm{~nm}$ and $232 \mathrm{~nm}$ were selected for the formation of simultaneous equation (Figure 3 ).

The calibration curves for PNT and LVS were prepared at $290 \mathrm{~nm}$ and $232 \mathrm{~nm}$ individually, and absorptivity values were determined. Calibration curves were found to be linear in the range of $4-12 \mu \mathrm{g} / \mathrm{mL}$ for PNT and $8-20 \mu \mathrm{g} / \mathrm{mL}$ for LVS.

The following formulae were established for the estimation of drugs in combined dosage form using simultaneous equation method:

$$
\begin{aligned}
& C_{\mathrm{PNT}}=\frac{\left[\left(A_{2} \times 50\right)-\left(A_{1} \times 340\right)\right]}{[141000]}, \\
& C_{\mathrm{LVS}}=\frac{\left[\left(A_{1} \times 400\right)-\left(A_{2} \times 450\right)\right]}{[141000]} .
\end{aligned}
$$

Precision studies were carried out to study the intraday and interday variations of the responses. Instrumental precision study was carried out by repeatability study. The low RSD value indicates that the method is precise (Table 1). Accuracy was determined by calculating the recoveries. The recoveries for PNT and LVS were found to be in the range of 100.24$100.99 \%$ and $100.52-100.95 \%$, respectively. Excipients used in the specificity studies did not interfere with the response of either of the drugs at their respective analytical wavelengths. In robustness study, no significant change in the response of both drugs was observed after $24 \mathrm{~h}$, and the percentage recovery for PNT and LVS was found to be 98.45-100.48 and $99.12-100.65 \%$, respectively. Hence the method is specific and robust for estimation of PNT and LVS. The validation parameters are summarized in Table 1.

Validity of the equations was checked by preparation of mixed standards (Table 2). The proposed method was applied 
to the determination of PNT and LVS in their combined capsule dosage forms. The results obtained were comparable with the corresponding labeled amounts (Table 3).

\section{Conclusion}

Simultaneous equation method has been developed for the estimation of PNT and LVS in their combined dosage form. The method was validated and found to be simple, sensitive, accurate, and precise. Simultaneous equation method is having advantage that it is simple, it requires less analysis time, and the cost of the analysis is less compared to chromatographic method. The method was successfully applied in the estimation of PNT and LVS in their combined dosage form.

\section{Acknowledgments}

The authors thank Balaji suppliers, Mumbai (India), and Corona Remedies Pvt. Ltd, Himachal Pradesh (India) for supplying gift samples of pantoprazole sodium and levosulpiride, respectively. The authors are highly thankful to Indukaka Ipcowala College of Pharmacy, New V.V.Nagar, Gujarat, India, for providing all the facilities to carry out the work.

\section{References}

[1] The Merck Index, Merck Research Laboratories, Division of Merck \& Co., 13th edition, 2011.

[2] J. E. F. Reynolds, Martindale the Extra Pharmacopoeia, The Royal Pharmaceutical Society, 31st edition, 1996.

[3] R. Lozano, M. G. P. Concha, A. Montealegre et al., "Effectiveness and safety of levosulpiride in the treatment of dysmotility-like functional dyspepsia," Therapeutics and Clinical Risk Management, vol. 3, no. 1, pp. 149-155, 2007.

[4] A. Mucci, G. Nolfe, and M. Maj, "Levosulpiride: a review of its clinical use in psychiatry," Pharmacological Research, vol. 31, no. 2, pp. 95-101, 1995.

[5] Indian Pharmacopoeia (Vol-I, II, III), Government of India "Ministry of Health \& Family Welfare" The Controller \& Publication, Delhi, India, 2010.

[6] P. R. Battu and N. K. K. Reddy, "Development and validation of RP-HPLC for the pantoprazole sodium sesquihydrate in pharmaceutical dosage forms and human plasma," International Journal of ChemTech Research, vol. 1, no. 2, pp. 195-198, 2009.

[7] S. Thanikachalam, M. Rajappan, and V. Kannappan, "Stabilityindicating HPLC method for simultaneous determination of pantoprazole and domperidone from their combination drug product," Chromatographia, vol. 67, no. 1-2, pp. 41-47, 2008.

[8] Rajnis kumar, P. Singh, and H. Singh, "Development and validation of RP-HPLC method for simultaneous estimation of naproxen and pantoprazole in pharmaceutical dosage form," International Journal of Pharmaceutical Research and Development, vol. 2, no. 12, pp. 227-232, 2011.

[9] A. G. Tated, F. A. Khan, C. K. Gadewar, R. L. Bakal, A. P. Dewani, and A. V. Chandewar, "Method development and validation for simultaneous determination of Naproxen and Pantoprazole sodium in capsule dosage form by RP-HPLC," International Journal of Pharmaceutical Research and Development, vol. 3, no. 5, pp. 8-14, 2011.
[10] S. Manjunath, V. Chouhan, and S. Sandeep, "Spectrophotometric estimation of Levosulpiride in bulk drug and formulations," International Journal of Pharmacy and Pharmaceutical Sciences, vol. 3, no. 2, pp. 135-137, 2011.

[11] Y. P. Agrawal, S. P. Gautam, A. Verma, M. Y. Agrawal, and A. K. Gupta, "Simultaneous estimation of esomeprazole and levosulpiride in solid dosage form," Der Pharmacia Sinica, vol. 3, no. 3, pp. 337-342, 2012.

[12] S. E. Jin, E. Ban, Y. B. Kim, and C. K. Kim, "Development of HPLC method for the determination of levosulpiride in human plasma," Journal of Pharmaceutical and Biomedical Analysis, vol. 35, no. 4, pp. 929-936, 2004.

[13] H. Patel, A. K. Shrivastava, and D. Jindal, "Analytical method development and validation of esomeprazole and levosulpiride in their combined capsule dosage form by RP-HPLC," International Journal For Pharmaceutical Research Scholars, vol. 1, no. 3, pp. 1-7, 2012.

[14] A. Sirisha and A. Ravi Kumar, "Method development and validation of simultaneous estimation of levosulpiride and rabeprazole in bulk and pharmaceutical dosage form by RP-HPLC," International Research Journal of Pharmaceutical and Applied Sciences, vol. 2, no. 4, pp. 49-55, 2012.

[15] M. Padmalatha, T. Snehalatha, S. Ramya, and M. Kanakadurga, "A simple and validated RP-HPLC method for the simultaneous estimation of Rabeprazole and Levosulpiride in bulk and pharmaceutical dosage forms," International Research Journal of Pharmaceutical and Applied Sciences, vol. 2, no. 2, pp. 99-106, 2012.

[16] V. Borakhatariya Dharanant, R. Marwada Kuldip, D. Patel Bhargav, F. Raiyani Lalit, and H. Patel Bhavesh, "Simultaneous estimation of pantoprazole sodium and levosulpiride in pharmaceutical dosage form by RP-HPLC method," Pharm Analysis \& Quality Assurance, vol. 2, no. 2, pp. 125-139, 2013. 

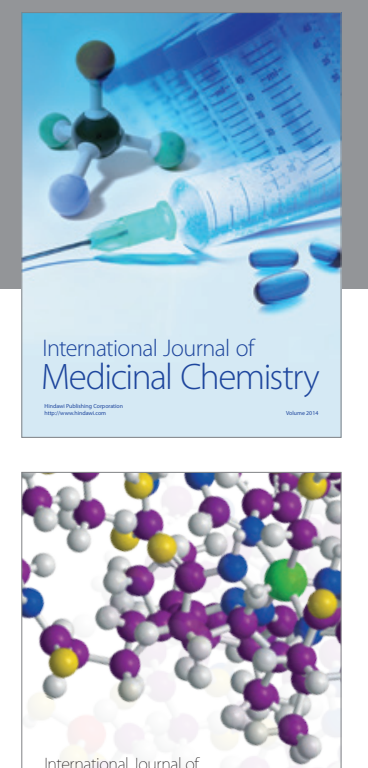

\section{Carbohydrate} Chemistry

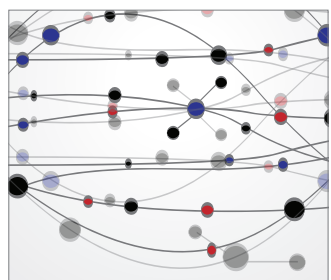

The Scientific World Journal
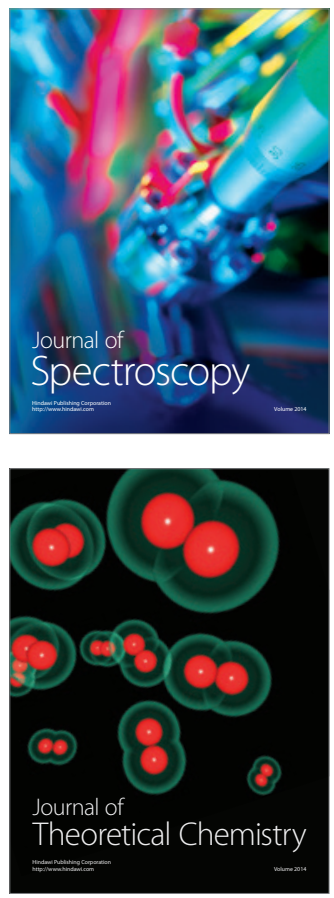
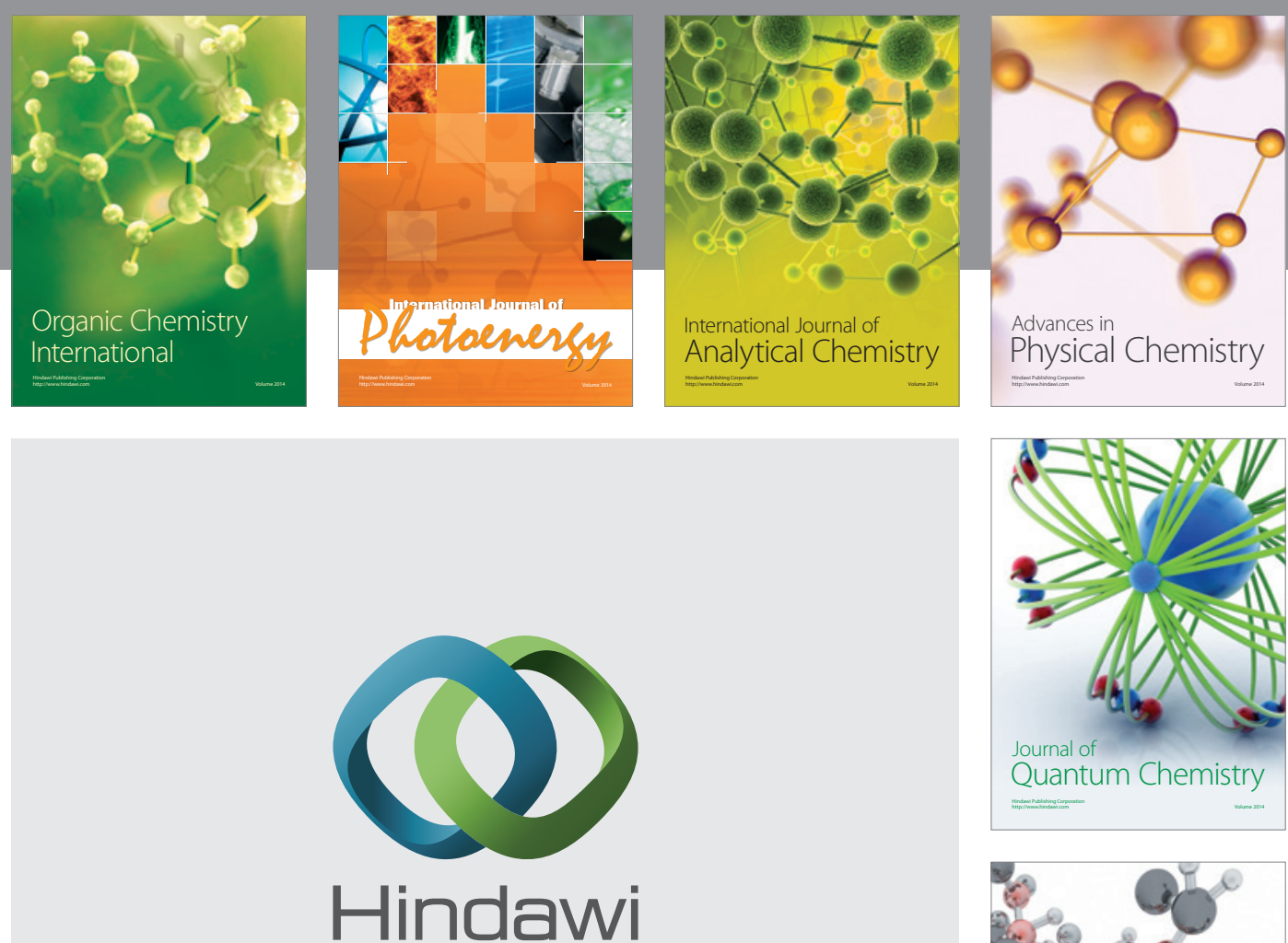

Submit your manuscripts at

http://www.hindawi.com

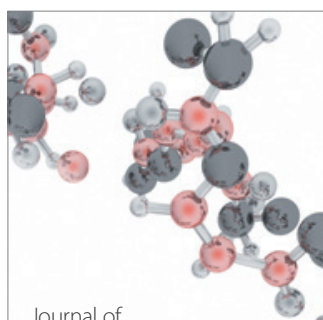

Analytical Methods

in Chemistry

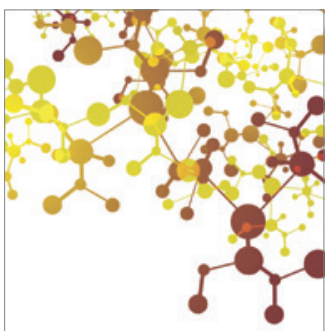

Journal of

Applied Chemistry

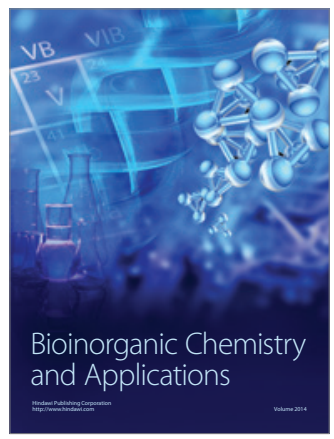

Inorganic Chemistry
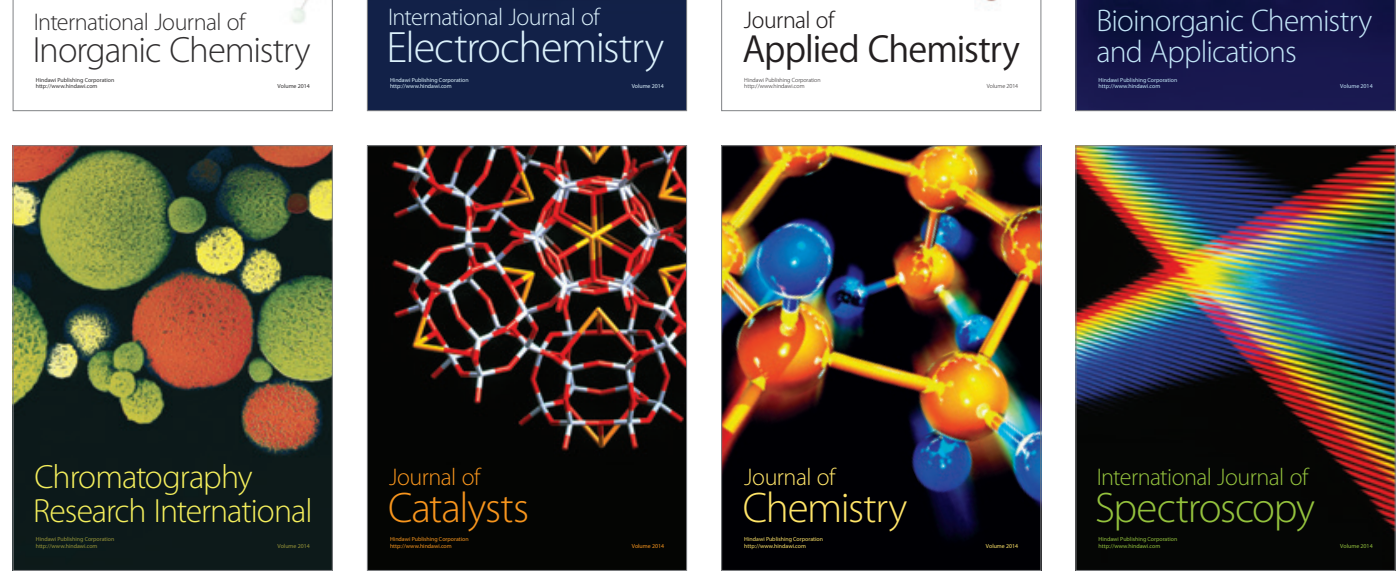